\title{
PTCH2 is not a strong candidate gene for gorlin syndrome predisposition
}

\author{
Miriam J. Smith ${ }^{1}$ (D) D. Gareth Evans ${ }^{1}[0$
}

Received: 1 April 2021 / Accepted: 16 June 2021 / Published online: 25 June 2021

(c) The Author(s) 2021

\begin{abstract}
A number of case/family reports have proposed $\mathrm{PTCH} 2$ as a putative Gorlin Syndrome (GS) gene, but evidence to support this is lacking. We assessed our cohort of 21 PTCH1/SUFU negative GS families for PTCH2 variants and assessed current evidence from reported cases/families and population data. In our PTCH1/SUFU variant negative GS cohort (25\% of total), no pathogenic or likely pathogenic $\mathrm{PTCH} 2$ variants were identified. In addition, none of the previously published $\mathrm{PTCH} 2$ variants in GS families/cases could be considered pathogenic or likely pathogenic using current guidelines. The absence of clear pathogenic variants in GS families and the high frequency of Loss-of-function (LoF) variants in the general population, including the presence of homozygous LoF variants without a clinical phenotype, mean that it is untenable that $P$ TCH2 is a GS gene. PTCH2 should not be included in panels for genetic diagnosis of GS.
\end{abstract}

Keywords Gorlin syndrome $\cdot$ Basal cell carcinoma $\cdot$ BCNS $\cdot$ NBCCS $\cdot$ PTCH2

\section{Introduction}

Gorlin syndrome (GS), also known as basal cell nevus syndrome (BCNS) and nevoid basal cell carcinoma syndrome (NBCCS) is an autosomal dominant tumour predisposition syndrome which predisposes affected individuals to the development of odontogenic jaw keratocysts and multiple basal cell carcinomas as well as a number of dysmorphic features and congenital abnormalities. Pathogenic variants in the PTCHI gene are the most common genetic abnormalities associated with GS [1]. Occasionally, variants in SUFU have been identified as the cause of classic GS with a much higher risk of infantile medulloblastoma (20-30\% risk) than PTCH1 related GS (1-2\% risk) and there is no real evidence for keratocysts in $S U F U$-associated GS [2, 3]. The identification of $\mathrm{PTCH} 2$ in 1999 [4] led to speculation that this may also be a cause of GS. Although no germline pathogenic variants were found in the initial report, somatic mutations

D. Gareth Evans

gareth.evans@mft.nhs.uk

1 Manchester Centre for Genomic Medicine, St Mary's Hospital, Manchester Academic Health Sciences Centre, Division of Evolution and Genomic Science, Faculty of Biology, Medicine and Health, The University of Manchester, Manchester M13 9WL, UK in a medulloblastoma and a basal cell carcinoma were found [4]. It was not until nine years later that two reports from China suggested that missense variants in $P T C H 2$ could be linked to GS $[5,6]$. $\mathrm{Xu}$ and $\mathrm{Li}$ reported the variants c.323 $\mathrm{T}>\mathrm{C}$ and c.1319C $>\mathrm{T}$ [6]. On recent review of the nomenclature, we noted that the variants are now annotated as c.311 T > C, p.Leu104Pro and c.1307C > T, p.Ala436Val. The first variant, p.Leu104Pro, is now known to occur in $73 / 282696$ alleles in gnomAD data (frequency $=0.000258$ ) (including 1 homozygote) (https://gnomad.broadinstitute. org/transcript/ENST00000372192 ? dataset $=$ gnomad_ r2_1) accessed December 21st 2020. The second variant, c. $1307 \mathrm{C}>\mathrm{T}$, p.Ala436Val, is found in 18/280892 alleles on gnom AD (frequency $=0.000064$ ). Another variant, reported by Fan et al. in one large family, is p.Arg719Gln [5]. This variant is found in $8 / 281616$ alleles on gnomAD (frequency $=0.000028$ ). Thus, these three variants, summarised in Table 1, have all been found multiple times in the gnomAD cohort and are too common to be a relatively minor genetic contributor to GS.

Since 2008, there have been two further reports of a family [7] and a single case [8] of PTCH2-associated GS. However, while GS features are described, these individuals did not meet clinical criteria.

Despite a report of a healthy woman in her late $30 \mathrm{~s}$ with a homozygous truncating variant, but no GS features, and with 
Table 1 Previous reports of germline $\mathrm{PTCH} 2$ variants associated with GS phenotype

\begin{tabular}{|c|c|c|c|c|c|}
\hline & $\begin{array}{l}\text { Family or } \\
\text { single case }\end{array}$ & Meets criteria & Variant & $\mathrm{ACMG}^{\mathrm{a}}$ classification & gnom $A D$ frequency \\
\hline Casano et al. [7] & Family & No & c.3347C > T; p.(Pro1116Leu) & 3 (Uncertain significance) & $2 / 247660(8.08 \mathrm{e}-6)$ \\
\hline Fujii et al. [8] & Case & No & c.1172_1173delCT; p.Ser391 ${ }^{\mathrm{a}}$ & $\begin{array}{l}\text { 2/3 (Likely benign/uncertain } \\
\text { significance) }\end{array}$ & $\begin{array}{l}\text { 64/282846 }(2.26 \mathrm{e}-4) \\
\text { (includes } 1 \\
\text { homozygote) }\end{array}$ \\
\hline Fan et al. [5] & Family & Yes & c. $2157 \mathrm{G}>\mathrm{A} ;$ p.Arg719Gln & 3 (Uncertain significance) & $8 / 281616(2.84 \mathrm{e}-5)$ \\
\hline Xu et al. [6] & Unclear & Unclear & c.311 T>C, p.Leu104Pro & 2 (Likely benign) & $\begin{array}{l}73 / 282696(2.58 \mathrm{e}-4) \\
\text { (includes } 1 \\
\text { homozygote) }\end{array}$ \\
\hline $\mathrm{Xu}$ et al. [6] & Unclear & Unclear & c. $1307 \mathrm{C}>\mathrm{T}$, p.Ala436Val & 3 (Uncertain significance) & $18 / 280892(6.41 \mathrm{e}-5)$ \\
\hline
\end{tabular}

${ }^{a}$ American College of Medical Genetics guidelines for variant classification[11]

a daughter who also has no GS features [9], review articles still cite $P T C H 2$ as a cause of GS [10]. We have therefore assessed the potential contribution of $\mathrm{PTCH} 2$ to GS in our own data, by assessing the gene in the germline of GS families who have previously been found negative for pathogenic $P T C H I$ and SUFU variants. We have also assessed the frequency of loss-of-function variants in gnomAD data.

\section{Materials and methods}

\section{Patient material}

A total of 86 unrelated individuals were identified as meeting clinical diagnostic criteria for Gorlin syndrome and as having undergone previous clinical genetic screening for pathogenic PTCHI variants using a combination of Sanger sequencing and multiplex ligation-dependent probe amplification (MLPA). For eight individuals with RNA samples available RNA analysis had also been undertaken. Lymphocyte DNA was available for further genetic analysis on all 27 people who tested negative for $\mathrm{PTCH} 1$ variants. Routine screening was carried out through the diagnostic service at the West Midlands Genetics Laboratory, UK. Research analysis was carried out with ethical approval by the National Research Ethics Service Committee North West 7 (10/ H1008/74).

\section{Mutational analysis}

DNA was purified using Zymo Genomic DNA Clean and Concentrator columns (Zymo Research Irvine, CA, USA) and exome sequencing analysis was carried out on lymphocyte DNA in-house using an Illumina HiSeq, or by BGI-Tech solutions (Hong Kong) Co Ltd, using paired-end 100 bp and sequenced to 50x. PTCH1, SUFU and PTCH2 variants were annotated using VarSeq software (Golden Helix Inc, MT, USA) and variant pathogenicity was assessed using
American College of Medical Genetics (ACMG) guidelines [11].

All variants detected by exome sequencing were subsequently validated by Sanger sequencing. Selected regions were amplified by PCR using GoTaq G2 PCR mastermix and products were purified using AxyprepMag PCR cleanup beads (Axygen Biosciences, CA, USA). DNA sequencing was performed using BigDye ${ }^{\circledR}$ Terminator v3.1 Cycle Sequencing Kit (ABI, Life Technologies, CA, USA). Sequencing PCR products were purified using Axyprep Mag DyeClean beads (Axygen Biosciences, CA, USA) and sequence analysis was performed using an ABI 3730xl DNA Analyzer (ABI, Life Technologies, USA).

\section{Copy number analysis}

Copy number analysis for detection of large deletions in PTCH1 used the PTCH1 SALSA MLPA probemix P067-B1-0512 PTCH1v13 (MRC-Holland, The Netherlands). The large $S U F U$ deletion was identified using an in-house assay designed in the laboratory of Dr Christian Beetz, and carried out as previously described [2].

\section{Results}

Lymphocyte DNA from a total of 86 unrelated individuals meeting clinical criteria for GS was screened for pathogenic PTCHI variants using Sanger sequencing and, where material was available, RNA analysis [2]. This identified pathogenic $P T C H 1$ variants in 59 people (68.6\%). Exome sequencing was carried out on the remaining 27 PTCHI negative individuals. This identified 2 more $P$ TCH1 variants that had been missed on historical clinical Sanger sequencing, perhaps due to the use of legacy transcript annotation. In addition, we have previously reported three families from this cohort with pathogenic $S U F U$ variants, found using a combination of sequencing and copy number analysis [2]. A 
fourth family has subsequently been identified with a pathogenic SUFU variant. Thus $65 / 86$ families $(75.6 \%)$ with GS have an identifiable $P T C H I$ or $S U F U$ causative variant. No pathogenic (class 5) or likely pathogenic (class 4) PTCH2 variants were identified in anyone from this cohort, according to the ACMG guidelines [11].

Assessment of $\mathrm{PTCH} 2$ loss-of-function variants identified in the gnomAD cohort, found 355 loss-of-function (frameshift, nonsense and canonical splice-site) variants in the canonical PTCH2 isoform (ENST00000372192.3), equivalent to 1 in 324 individuals, including a single case of a female who was homozygous for p.Ser $391^{*}$, the same variant identified in the case reported by Fujii et al. [8] and more recently in a report of a Korean patient who also did not fulfil clinical diagnostic criteria for Gorlin syndrome [12].

In addition, 1 in 44 individuals on gnomAD were found to carry a rare missense $(<0.0002$ population allele frequency) and 1 in 17 carried a missense with a population allele frequency of $0.0002-0.01$. Therefore, there is a $2-6 \%$ chance of finding at least a class 3 variant of uncertain significance (VUS) when screening $\mathrm{PTCH} 2$.

\section{Discussion}

Given that the estimated birth incidence of GS is around 1 in 15,000 and that over $75 \%$ of these are accounted for by $P T C H 1$ and $S U F U$, only the equivalent of around 1 in 60,000 can be due to other genes. Despite a rate of loss-of-function variants of 1 in 324 in the general population, $P T C H 2$ did not account for any of our 21 clinically affected unfound families. In addition to our 21 families and the 22 families from the original $\mathrm{PTCH} 2$ gene discovery report [4], it is likely that many more GS families have been screened for $\mathrm{PTCH} 2$ variants, yet only one truncating variant has been reported and this is present at a high frequency in gnomAD and has also been seen in homozygous form. It is possible, even likely, that over 300 people have been screened and meaning that finding one variant is consistent with chance. None of the reported missense variants that are also frequent in gnomAD would be classified as pathogenic or likely pathogenic, according to ACMG guidelines. In particular, the c.311 T > C, p.Leu104Pro is classified as class 2 or lower due to frequency and homozygosity. It is therefore simply untenable that $P T C H 2$ is a bone fide GS predisposition gene and at most may act as a modifier of the phenotype. PTCH2 should therefore not be included in panels to identify GS causing variants and individuals identified with a $\mathrm{PTCH} 2$ variant incidentally should be reassured that it is likely to be of no particular consequence and is certainly not a risk for GS.
Acknowledgements MJS and DGE are supported by the Manchester NIHR Biomedical Research Centre (IS-BRC-1215-20007). DGE has received travel grants from AstraZeneca.

Author contributions DGE conceived the study. MJS and DGE analysed the data, and drafted and revised the manuscript.

Funding MJS and DGE are supported by the Manchester NIHR Biomedical Research Centre (IS-BRC-1215-20007).

Data availability Anonymised data are available from the authors on request.

\section{Declarations}

Conflict of interest DGE has received travel Grants from AstraZeneca.

Ethical approval Routine screening was carried out through the diagnostic service at the West Midlands Genetics Laboratory, UK. Research analysis was carried out with ethical approval by the National Research Ethics Service Committee North West 7 (10/H1008/74).

Open Access This article is licensed under a Creative Commons Attribution 4.0 International License, which permits use, sharing, adaptation, distribution and reproduction in any medium or format, as long as you give appropriate credit to the original author(s) and the source, provide a link to the Creative Commons licence, and indicate if changes were made. The images or other third party material in this article are included in the article's Creative Commons licence, unless indicated otherwise in a credit line to the material. If material is not included in the article's Creative Commons licence and your intended use is not permitted by statutory regulation or exceeds the permitted use, you will need to obtain permission directly from the copyright holder. To view a copy of this licence, visit http://creativecommons.org/licenses/by/4.0/.

\section{References}

1. Evans DG, Farndon PA (1993) Nevoid basal cell carcinoma syndrome. In: Pagon RA, Adam MP, Ardinger HH, Bird TD, Dolan CR, Fong CT et al (eds) GeneReviews(R). University of Washington, Seattle

2. Smith MJ, Beetz C, Williams SG, Bhaskar SS, O'Sullivan J, Anderson B, Daly SB, Urquhart JE, Bholah Z, Oudit D, Cheesman E, Kelsey A, McCabe MG, Newman WG, Evans DG (2014) Germline mutations in SUFU cause Gorlin syndrome-associated childhood medulloblastoma and redefine the risk associated with PTCH1 mutations. J Clin Oncol 32:4155-4161

3. Evans DG, Oudit D, Smith MJ, Rutkowski D, Allan E, Newman WG, Lear JT (2017) First evidence of genotype-phenotype correlations in gorlin syndrome. J Med Genet 54:530-536

4. Smyth I, Narang MA, Evans T, Heimann C, Nakamura Y, Chenevix-Trench G, Pietsch T, Wicking C, Wainwright BJ (1999) Isolation and characterization of human patched 2 ( $\mathrm{PTCH} 2)$, a putative tumour suppressor gene inbasal cell carcinoma and medulloblastoma on chromosome 1p32. Hum Mol Genet 8:291-297

5. Fan Z, Li J, Du J, Zhang H, Shen Y, Wang CY, Wang S (2008) A missense mutation in PTCH2 underlies dominantly inherited NBCCS in a Chinese family. J Med Genet 45:303-308 
6. Xu LL, Li TJ (2008) PTCH2 gene alterations in keratocystic odontogenic tumors associated with nevoid basal cell carcinoma syndrome. Beijing Da Xue Xue Bao Yi Xue Ban 40:15-18

7. Casano K, Meddaugh H, Zambrano RM, Marble M, Torres JI, Lacassie Y (2020) Gorlin-like phenotype in a patient with a PTCH2 variant of uncertain significance. Eur J Med Genet 63:103842

8. Fujii K, Ohashi H, Suzuki M, Hatsuse H, Shiohama T, Uchikawa H, Miyashita T (2013) Frameshift mutation in the PTCH2 gene can cause nevoid basal cell carcinoma syndrome. Fam Cancer 12:611-614

9. Altaraihi M, Wadt K, Ek J, Gerdes AM, Ostergaard E (2019) A healthy individual with a homozygous PTCH2 frameshift variant: are variants of PTCH2 associated with nevoid basal cell carcinoma syndrome? Hum Genome Var 6:10

10. Onodera S, Nakamura Y, Azuma T (2020) Gorlin syndrome: recent advances in genetic testing and molecular and cellular biological research. Int J Mol Sci 21:7559
11. Richards S, Aziz N, Bale S, Bick D, Das S, Gastier-Foster J, Grody WW, Hegde M, Lyon E, Spector E, Voelkerding K, Rehm HL, Committee ALQA (2015) Standards and guidelines for the interpretation of sequence variants: a joint consensus recommendation of the American College of Medical Genetics and Genomics and the association for molecular pathology. Genet Med 17:405-424

12. Kwon WK, Kim HT, Yoon YC, Woo HI, Kim J-W (2020) The first Korean case of Gorlin-Goltz syndrome caused by a PTCH2 pathogenic variant identified via whole exome sequencing. Lab Med Online 10:175-178

Publisher's Note Springer Nature remains neutral with regard to jurisdictional claims in published maps and institutional affiliations. 